\title{
Effects of walking with hand-held weights on energy expenditure and excess postexercise oxygen consumption
}

\author{
Catherine T. Campaña, Pablo B. Costa* \\ Department of Kinesiology, California State University - Fullerton, Fullerton, CA, USA
}

Walking is not only important to assist in performing daily tasks, but also to gain cardiovascular benefits. Further research on walking is needed to examine the physiological responses to improve health and reduce the risks of cardiovascular disease. The purpose of this study was to compare the energy expenditure (EE) during and after walking exercise with versus without hand-held weights (HHW). Nineteen sedentary women (mean \pm standard deviation; age, $21 \pm 2.7$ years, height, $163.1 \pm 6.3$ cm; body mass, $66.6 \pm 15.1 \mathrm{~kg}$; body fat $\%, 30.6 \% \pm 7.43 \%$; body mass index, $25.5 \pm 5.7 \mathrm{~kg} / \mathrm{m}^{2}$ ) volunteered walking with versus without $1.36 \mathrm{~kg}$ of HHW in two randomized sessions. The study consisted of $30 \mathrm{~min}$ of exercise followed b silent sitting for $30 \mathrm{~min}$. The range of motion was set at elbow flexion at $90^{\circ}$ while arms were alternated $30.48 \mathrm{~cm}$ forward and backward. $1 \%$ incline was set for the treadmill grade and speed was controlled to a moderate level of $40 \%-59 \%$ of heart rate reserve. During the 30-min exercise no significant differences were found between the conditions $(P>0.05)$. The physiological responses were significantly greater directly after exercise compared with baseline as determined from pairwise comparisons collapsed across conditions $(P \leq 0.05)$. Walking with HHW was not substantial enough to raise EE beyond normal walking and led to an increased effort level. Additionally, the moderate intensity of walking was not enough to sustain EE at a surpassing level directly after the exercise.

Keywords: Cardiovascular disease, Aerobic exercise, Moderate intensity, Dumbbells, Physical fitness, Metabolic responses

\section{INTRODUCTION}

According to the 2013 mortality rate data, more than 2,200 Americans die every day due to cardiovascular disease (Mozaffarian et al., 2016). This disease disrupts the vascular system as well as having the potential to damage the body's vital organs including the heart and brain (Basson, 2008). It has been reported that performing moderate-intensity exercise 2 days a week for $30 \mathrm{~min}$ may reduce the mortality risks from cardiovascular disease in sedentary obese adults (Apekey et al., 2012). Those who do not participate in any form of exercise may start with a simple and safer activity such as walking to increase their fitness level (Wen et al., 2014). Accordingly, walking durations of $30 \mathrm{~min}$ are considered an aerobic or cardiorespiratory form of exercise and could be mod- ified to an activity with higher intensity (Graves et al., 1987).

In previous studies, intensity was shown to be a key component in how energy levels are affected during the exercise one participates in, especially while walking with hand-held weights (HHW) (Evans et al., 1994; Morrow et al., 1992; Owens et al., 1989). Key factors contributing to the caloric expenditure and exercise intensity from walking while moving HHW were arm range of motion and walking speed (Morrow et al., 1992). However, another investigation reported intensity is enhanced through both carrying HHW and greater arm range of motion (Makalous et al., 1988). Other studies also reported arm motion is crucial for increasing energy cost (Auble et al., 1987; Maud et al., 1990). Two studies had arms begin at the sides and moving hands up to waist level $90^{\circ}$ (Makalous et al., 1988; Zarandona et al., 1986). One used a
${ }^{*}$ Corresponding author: Pablo B. Costa (ib) https://orcid.org/0000-0002-4504-5160 Department of Kinesiology, California State University - Fullerton, 800 N. State College Blvd., KHS 254, Fullerton, CA, 92831, USA

Tel: +1-657-278-4232, Fax: +1-657-278-2103, E-mail: pcosta@fullerton.edu Received: August 14, 2017 / Accepted: December 5, 2017
This is an Open Access article distributed under the terms of the Creative Commons Attribution Non-Commercial License (http://creativecommons.org/licenses/by-nc/4.0/) which permits unrestricted non-commercial use, distribution, and reproduction in any medium, provided the original work is properly cited. 
normal arm range of motion (Owens et al., 1989) while another used normal arm swings while hands passed the shoulder and behind the gluteus maximus for vigorous arm swings (Maud et al., 1990). Others lifted to shoulder height while the opposite elbow flexed at $90^{\circ}$ (Graves et al., 1987) or lifted $30.48 \mathrm{~cm}$ forward and upward exceeding $90^{\circ}$ elbow flexion (Knowlton et al., 1992) Additionally, carrying $1.36 \mathrm{~kg}$ HHW was needed to significantly increase metabolic costs during the exercise (Knowlton et al., 1992; Zarandona et al., 1986).

Excess post-exercise oxygen consumption (EPOC) is the elevated postexercise metabolism which adds to the energy expenditure (EE) of the exercise and as a component of the thermic effect of the activity (Laforgia et al., 2006). Two energy systems, phosphocreatine and anaerobic glycolytic systems, provide sources of energy to the body while exercising (Chandler and Brown, 2012). When these energy supplies deplete during exercise, the oxidative system mainly supplies energy for the body, whereas EPOC replenishes the anaerobic system postexercise (Chandler and Brown, 2012). To our knowledge, no study has investigated the effects of treadmill walking with $\mathrm{HHW}$ that specifically based the intensity at a moderate level of $40 \%-59 \%$ using the Karvonen heart rate (HR) reserve method, nor examined its effects on EPOC. Therefore, the purpose of this study was to compare the physiological responses in sedentary women between treadmill walking with versus without $1.36 \mathrm{~kg} \mathrm{HHW}$ at a moderate level of intensity on $\mathrm{EE}$, oxygen uptake $\left(\mathrm{VO}_{2}\right), \mathrm{HR}$, amount of fat and carbohydrates $(\mathrm{CHO})$ expended, respiratory exchange ratio (RER), rating of perceived exertion (RPE), and EPOC.

\section{MATERIALS AND METHODS}

\section{Participants}

Nineteen college-age women, mean \pm standard deviation, $21 \pm 2.7$ years old, $66.61 \pm 15.11 \mathrm{~kg}$, and $163.1 \pm 6.3 \mathrm{~cm}$ tall, volunteered and completed the research study. The study focused on women because this population seemed to engage more often in walking with HHW compared to men. In addition, male participants were more prevalent participants in previous studies compared to females. Physical characteristics of the participants are summarized in Table 1.

The participants were either sedentary or had not taken part in any exercise within the previous six months prior to participation. Exclusion criteria included having hypertension or other cardiovascular medical conditions that would prevent them from being capable to participate in the study. No medication was used by
Table 1. Characteristics of the participants

\begin{tabular}{lc}
\hline Variable & Mean $\pm S D$ \\
\hline Age $(\mathrm{yr})$ & $21 \pm 2.7$ \\
Body mass $(\mathrm{kg})$ & $66.6 \pm 15.1$ \\
Height $(\mathrm{cm})$ & $163.1 \pm 6.3$ \\
Waist-to-hip ratio $(\mathrm{cm})$ & $0.74 \pm 0.05$ \\
Body fat percentage $(\%)$ & $30.6 \pm 7.4$ \\
Body mass index $\left(\mathrm{kg} / \mathrm{m}^{2}\right)$ & $25.5 \pm 5.7$ \\
Fat mass $(\mathrm{kg})$ & $21.0 \pm 9.4$ \\
Lean body mass $(\mathrm{kg})$ & $45.0 \pm 6.8$
\end{tabular}

SD, standard deviation.

the participants that affected their HR or blood pressure. Participants were also not allowed to consume caffeine or alcohol $24 \mathrm{hr}$ before the testing sessions and fasted for at least one hour with the exception of water before the testing began. The attire worn during the study was comfortable exercise clothing and tennis shoes. This study was approved by the Institutional Review Board of California State University, Fullerton (approval number: HSR-15-0275). An informed consent document was given to each participant who signed prior to participating in the study.

\section{Research design}

Sedentary or untrained women volunteered for the study and visited the laboratory on two randomly-ordered sessions. Both sessions consisted of one exercise protocol and an EPOC period that lasted for approximately $1 \mathrm{hr}$ combined. The two sessions were completed at least one day apart and were randomly ordered to have the participant move their arms either with $1.36 \mathrm{~kg} \mathrm{HHW}$ or without HHW during treadmill walking.

During the first visit, the participant was seated and given an informed consent to read the procedures and sign to agree to the conditions of the study. A Pre-Exercise Testing Health \& Exercise Questionnaire was also given for the participant to complete to make certain her health status was suitable for the study. If acceptable, the next appointment was scheduled. Then, the participant's resting HR was taken after at least 10 min of seated rest by relaxing her arm in a supine position and using the tips of four fingers, excluding the thumb to press onto the radial artery of the thumb side of her wrist (Yim and Park, 2014). When the pulse was felt, HR was assessed for 1 min and then recorded (Yim and Park, 2014). The maximum HR prediction was calculated using the formula: $\mathrm{HR}_{\max }=192-\left(0.007 \times \mathrm{age}^{2}\right)$ (American College of Sports Medicine [ACSM] 2014). To calculate maximum HR reserve the following formula was used: $\mathrm{HR}_{\text {reserve }}=\mathrm{HR}_{\max }-\mathrm{HR}_{\text {rest }}$ (Graves et al., 1987). Moderate intensity was set between 40\%-59\% (ACSM, 2014). 
The target HR (THR) was calculated using: $\mathrm{THR}_{40 \%}=\mathrm{HR}_{\text {rest }}+$ $0.40\left(\mathrm{HR}_{\max }-\mathrm{HR}_{\text {rest }}\right)$ and $\mathrm{THR}_{59 \%}=\mathrm{HR}_{\text {rest }}+0.59\left(\mathrm{HR}_{\max }-\mathrm{HR}_{\text {rest }}\right)$ (Kenney et al., 2012).

Next, the anthropometrics of each participant were measured, which consisted of their body mass, height, and body composition. First, the participant removed her shoes before stepping onto the digital scale (Ohaus ES Series scale, Parsippany, NJ, USA) where her body mass was measured and recorded in $\mathrm{kg}$. Then, with her shoes removed, she stood tall against the stadiometer (Seca stadiometer, Chino, CA, USA) and after the participant took one deep breath, her height was measured in $\mathrm{cm}$. To obtain the circumferences of the hip and waist, a spring-loaded tape measurer (GulickBaseline Evaluation Instruments tape measurer, Knoxville, TN, USA) was used to measure the areas in centimeters. The waist was measured around the narrowest portion between the ribs and the hip bone (ACSM, 2014). The hip was measured on the widest portion around the hips and the gluteus maximus (ACSM, 2014). The waist-to-hip ratio was calculated by dividing the hip by the waist in cm (ACSM, 2014).

In addition to the waist-to-hip ratio, the participant's body fat $(\mathrm{BF} \%)$ was measured with a skinfold caliper (Harpenden Skinfold Caliper, Sussex, England) using the Jackson and Pollock 7-site method (ACSM, 2014). The seven sites included the chest, subscapular, midaxillary, triceps, abdominal, suprailiac, and thigh folds (ACSM, 2014). Body density $\left(D_{B}\right)$ was calculated using: $D_{B}$ $=1.097-(0.00046971 \times$ sum of seven skinfolds $)+[0.00000056 \times$ (sum of seven skinfolds $\left.{ }^{2}\right)-(0.00012828 \times$ age $\left.)\right]($ ACSM, 2014). Then, the BF\% was calculated using the Siri equation: $\mathrm{BF} \%=$ $\left(495 \div \mathrm{D}_{\mathrm{B}}\right)-450$ (ACSM, 2014). Fat body mass which is the mass of the $\mathrm{BF} \%$ was calculated as: fat body mass $=(\mathrm{BF} \% \times$ body mass $)$ $\div 100$ (Siri, 1993). The lean body mass was calculated by taking the difference between the body mass and the fat body mass (Siri, 1993).

After all skinfolds were taken, the participant was instructed on proper arm and leg motion. The correct arm motion for the current study was to flex $90^{\circ}$ at the elbow (about waist level), while alternating each arm forward and backward (Evans et al., 1994). Both elbows were constantly flexed throughout the entire exercise trial and alternated approximately $30.48 \mathrm{~cm}$ forward and 30.48 cm backward from the waist (Evans et al., 1994). As the arm motion was performed, the opposite leg was to be in front with the opposite arm (elbow flexing at $90^{\circ}$ ) in front (Auble et al., 1987; Evans et al., 1994).

During extensive piloting, moving $2.27 \mathrm{~kg} \mathrm{HHW}$ was too challenging for the moderately active to very active participants as they were unable to complete the entire 30 min of physical activity at the prescribed motion. To avoid increasing the risk of pain and injury of the participants, less heavy weights were used for the women who do not exercise. Thus, the sedentary women used $1.36 \mathrm{~kg}$ HHW during the current investigation. The participants' arm range of motion was measured through close observations by the investigator. If failing to meet the prescribed motion, verbal communication was given to assist participants in correcting their arm range of motion.

The Borg RPE scale was explained to the participant such that she could point to a number on the scale during the exercise test (ACSM, 2014). The participant was equipped with a HR monitor and a mouthpiece, which held in place a two-way rebreathing valve (Hans-Rudolph Inc., Shawnee, KS, USA). The rebreathing valve, where respiratory gases were collected, and mouthpiece were also attached to a headgear. Participants wore a nose clip to ensure that breathing occurred entirely through the mouth.

Then the participant sat for 5 min with the equipment remaining attached for the baseline period. After 5 min of quiet sitting, the participant transferred to the treadmill where she performed a 5-min warm-up with the arm and leg motion described previously, as the treadmill intensity was gradually increased. Based on the American College of Sports Medicine, the intensity recommendation was to be constant (ACSM, 2014). The speed of the treadmill was adjusted to match a moderate level of the THR of the participant and treadmill grade was raised to $1 \%$ to mimic outdoor walking. The exercise was performed after the warm-up, which was when the participant walked with the specified motion for $30 \mathrm{~min}$. This was the control exercise trial without HHW. When the participant completed the exercise test, she sat on a chair for $30 \mathrm{~min}$ to have these same measurements assessed during the EPOC period.

Treadmill speed and RPE based on the Borg scale was obtained every 5 min during the exercise test. $\mathrm{EE}$, fat expenditure, $\mathrm{CHO}$ expenditure, $\mathrm{VO}_{2}$, RER, and $\mathrm{HR}$ were collected every min throughout the entire exercise test and EPOC period using a calibrated metabolic cart (Parvo Medics TrueOne 2400 Metabolic Measurement System, Sandy, UT, USA). The metabolic cart was calibrated prior to each test with room air and standard gases of known volume and concentration for the oxygen $\left(\mathrm{O}_{2}\right)$ and carbon dioxide $\left(\mathrm{CO}_{2}\right)$ analyzers. $\mathrm{O}_{2}$ and $\mathrm{CO}_{2}$ were analyzed through a sampling line after the gasses passed through a heated pneumotach and mixing chamber.

For the second visit, the participant's resting HR was recorded in the same manner as the first visit. The participant practiced the specified arm and leg motion used in the first visit while lightly 
grasping and moving the $1.36 \mathrm{~kg} \mathrm{HHW}$. The $1.36 \mathrm{~kg} \mathrm{HHW}$ (Tone Fitness, Houston, TX, USA) were secured with velcro straps to the participant's hands to help hold the HHW in place such that the participants would not have to be concerned with the HHW sliding or falling. Once comfortable with the motion, the participant sat for 5 min with the HR monitor, nose, head, and mouth equipment pieces attached. Following the 5-min baseline period, the participant performed a 5-min warm-up on the treadmill with the specified motion learned and the intensity was gradually increased. Next, the exercise test began for 30 min with the arm and leg motion and with $1.36 \mathrm{~kg}$ HHW. In both visits, instruction was given to remind the participant of the proper arm and leg motion, if needed. $\mathrm{EE}$, fat expenditure, $\mathrm{CHO}$ expenditure, $\mathrm{VO}_{2}$, RER, treadmill speed, RPE, and $\mathrm{HR}$ were collected in the same manner as the first visit. When the exercise test was completed, the participant sat on a chair for $30 \mathrm{~min}$ for EPOC to be measured. Fig. 1 summarizes the overall research design of the study.

\section{Statistical analysis}

$\mathrm{EE}$, fat expenditure, $\mathrm{CHO}$ expenditure, $\mathrm{HR}, \mathrm{VO}_{2}$, $\mathrm{RER}$, treadmill speed, and RPE responses were evaluated using multiple twoway analysis of variance (ANOVAs) (time $\times$ condition) to compare the two different conditions of HHW and control. In the twoway ANOVA, if an $F$ was significant, one-way ANOVAs and post boc Tukey tests were used when appropriate to determine which

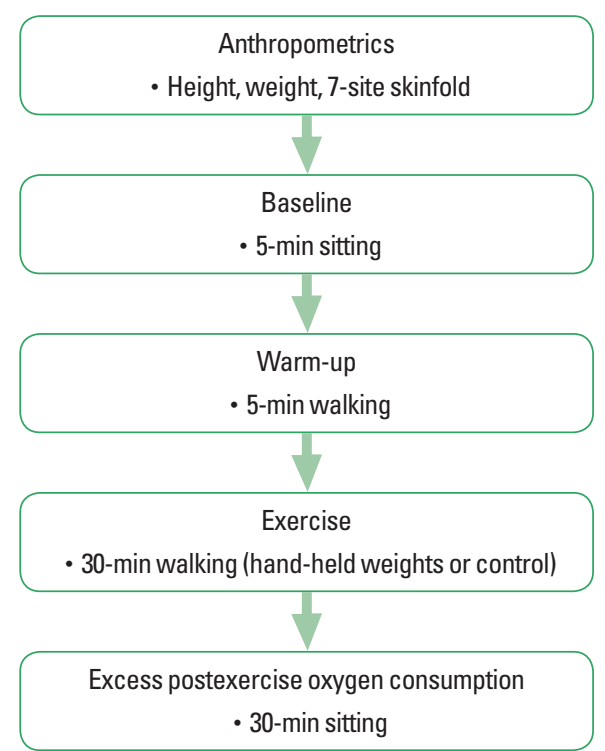

Fig. 1. The research design of the study outlines the procedures for the handheld weight and control visits. mean differences were significant. An alpha level of $P \leq 0.05$ was considered to be statistically significant. All statistical analyses were conducted using IBM SPSS Statistics ver. 23.0 (IBM Co., Armonk, NY, USA).

\section{RESULTS}

There was a main effect for time for EPOC $(F=165.253, P \leq$ 0.001). Pairwise comparisons collapsed across conditions indicated relative $\mathrm{VO}_{2}(\mathrm{~mL} / \mathrm{kg} / \mathrm{min})$ was $176.8 \%$ higher immediately after exercise compared with baseline $(P \leq 0.001)$ as shown in Fig. 2 . No other significant differences were found among other time points during EPOC $(P>0.05)$.

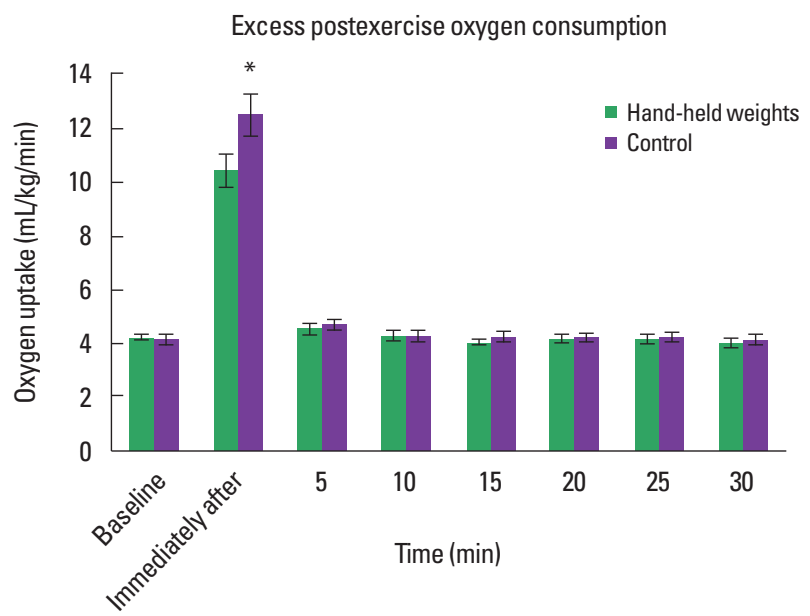

Fig. 2. Mean \pm standard error of participants' relative oxygen uptake during baseline and after exercise. Relative $\mathrm{VO}_{2}$ was significantly higher immediately after the exercise compared to baseline $\left(^{*} P<0.05\right)$.

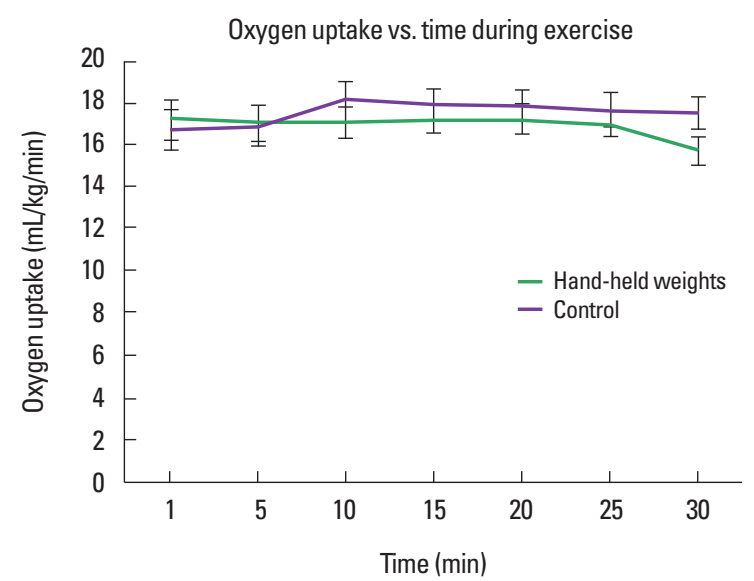

Fig. 3. Mean \pm standard error of participants' relative oxygen uptake during exercise. There were no significant differences between conditions $(P>0.05)$. 
Table 2. Metabolic and other variable responses to hand-held weight (HHW) and the control conditions during and after the exercise

\begin{tabular}{|c|c|c|c|c|}
\hline \multirow{2}{*}{ Variable } & \multicolumn{2}{|c|}{ During exercise } & \multicolumn{2}{|c|}{ After exercise } \\
\hline & HHW & Control & HHW & Control \\
\hline Heart rate (beats/min) & $137.00 \pm 1.62$ & $134.00 \pm 2.03$ & $94.0 \pm 2.00$ & $91.00 \pm 1.70$ \\
\hline Oxygen uptake (mL/kg/min) & $16.82 \pm 0.665$ & $17.41 \pm 0.717$ & $5.08 \pm 0.183$ & $5.46 \pm 0.21$ \\
\hline Energy expenditure (kcal/min) & $5.27 \pm 0.21$ & $5.44 \pm 0.21$ & $1.56 \pm 0.04$ & $1.70 \pm 0.05$ \\
\hline Carbohydrate expenditure (kcal/min) & $2.43 \pm 0.23$ & $2.59 \pm 0.21$ & $0.47 \pm 0.06$ & $0.60 \pm 0.67$ \\
\hline Fat expenditure (kcal/min) & $2.86 \pm 0.23$ & $2.89 \pm 0.19$ & $1.10 \pm 0.057$ & $1.08 \pm 0.70$ \\
\hline Respiratory exchange ratio & $0.83 \pm 0.01$ & $0.84 \pm 0.01$ & $0.79 \pm 0.01$ & $0.80 \pm 0.01$ \\
\hline Treadmill speed (mph) & $3.10 \pm 0.11$ & $3.50 \pm 0.08$ & - & - \\
\hline Rating of perceived exertion & $12.89 \pm 0.29$ & $11.62 \pm 0.29$ & - & - \\
\hline
\end{tabular}

Values are presented as mean \pm standard error.

Overall, there were no significant differences for $\mathrm{EE}(F=2.946$, $P=0.103)$, fat expenditure $(F=0.01, P=0.92)$, $\mathrm{CHO}$ expenditure $(F=0.319, P=0.579), \mathrm{VO}_{2}(F=0.319, P=0.579), \mathrm{RER}(F=0.034$, $P=0.855)$, or $\mathrm{HR}(F=3.395, P=0.082)$ between conditions during the exercise $(P>0.05)$. There was a main effect for condition for treadmill speed $(F=23.711, P \leq 0.001)$. Speed was $11.5 \%$ higher for the control compared to the HHW condition. In addition, there was a main effect for condition for RPE $(F=28.551, P \leq 0.001)$. RPE was $9.91 \%$ higher for the HHW compared to the control condition. Fig. 3 displays $\mathrm{VO}_{2}$ during the exercise. The mean and standard error for each variable collected during the study are displayed on Table 2 .

\section{DISCUSSION}

The main result of this study was a significant difference during EPOC for EE, which lasted no longer than 5 min after the end of the exercise. Although the EE was significant immediately after 5 min of exercise, EPOC did not remain elevated for a longer period. An explanation for this may be due to the controlled moderate-intensity of the treadmill walking exercise. Climactic increases in $\mathrm{VO}_{2}$ occurred with increasing walking speed rather than adding HHW at a fixed speed (Owens et al., 1989). In general, walking with HHW decreased the intensity of normal walking while the participant was walking on the treadmill (Morrow et al., 1992). It appears that a sufficient arm motion with a greater HHW load will increase the EE; however, this was influenced with a slower pace of walking, thus decreasing the walking speed (Morrow et al., 1992).

Since the treadmill speed was adjusted to match HR with a moderate intensity between $40 \%-59 \%$, there may not have been any additional $\mathrm{EE}$ benefits because $\mathrm{HR}, \mathrm{VO}_{2}$, and $\mathrm{REE}$ are linear- ly related to the workload (Zarandona et al., 1986). Instead, the current investigation supported the findings from another study that reported no additional benefits were obtained from carrying HHW with a constant THR intensity (Evans et al., 1994). The study compared a self-chosen pace and altered HR intensity at $70 \% \mathrm{HR}_{\text {reserve }}$ across conditions with $0,0.45,1.36$, and $2.27 \mathrm{~kg}$ in older adults (Evans et al., 1994). The arm range of motion was nearly identical with $90^{\circ}$ elbow flexion; however, the current study specified arms to move $30.48 \mathrm{~cm}$ forward and backward whereas the previous study used normal arm movements (Evans et al., 1994). Maintaining a constant THR resulted in similar EE (no differences in $\mathrm{VO}_{2}, \mathrm{VE}, \mathrm{RER}$, and RPE) with different $\mathrm{HHW}$ volumes or weight levels (Evans et al., 1994).

On the contrary, an advantage of using THR is that the metabolic demand remains the same despite decreasing speed and increasing volume of weight carried (Evans et al., 1994). The current investigation for the HHW condition resulted in a $12.9 \%$ lower treadmill speed and a higher RPE by $9.9 \%$ compared to the control condition. This particularly helps older adults or those who are working to achieve a training level to meet their THR without having to walk faster (Evans et al., 1994; Graves et al., 1987; Zarandona et al., 1986). More HHW volume contributes to stressing the body which may help adults to eventually increase their walking speed through training and after the removal of HHW.

While there were no additional EE benefits observed in this study during the exercise, another investigation reported benefits from walking with HHW (Evans et al., 1994). For instance, patients with myocardial infarction had improved ischemic thresholds when walking with HHW (Evans et al., 1994). It was suggested by the researchers that patients with myocardial infarction who walk while moving HHW had small increases in diastolic 
blood pressure which caused effusion of the blood flow and consequently increased the myocardial oxygen supply (Evans et al., 1994).

To our knowledge, no study has examined sedentary or untrained women, and included $5 \mathrm{~min}$ of sitting, a warm-up, and $30 \mathrm{~min}$ of exercise followed by subsequent quiet sitting for $30 \mathrm{~min}$. In addition, participants' arm range of motion, alternating $30.48 \mathrm{~cm}$ forward and backward while maintaining elbow flexion (bent) at $90^{\circ}$ for both sessions during the warm-up and exercise, was not examined in other studies.

Individuals casually walk with weights as part of their physical activity to increase the amount of calories expended. However, walking with $1.36 \mathrm{~kg}$ HHW for 30 min between $40 \%-59 \%$ of their THR was not enough to achieve greater EE during the exercise. Since EE was not significantly different, individuals may want to consider walking at more vigorous intensities or varying their HR training zones.

\section{CONFLICT OF INTEREST}

No potential conflict of interest relevant to this article was reported.

\section{ACKNOWLEDGMENTS}

The authors kindly appreciate the help of the participants during the study.

\section{REFERENCES}

American College of Sports Medicine. ACSM's guidelines for exercise testing and prescription. 9th ed. Philadelphia (PA): Lippincott Williams \& Wilkins; 2014.

Apekey TA, Morris AE, Fagbemi, S, Griffiths GJ. Benefits of moderate-intensity exercise during a calorie-restricted low-fat diet. Health Educ J 2012;71:154-164

Auble TE, Schwartz L, Robertson RJ. Aerobic requirements for moving handweights through various ranges of motion while walking. Phys Sportsmed 1987;15:133-140.

Basson M. Cardiovascular disease. Nature 2008;451:903.

Chandler JT, Brown LE. Conditioning for strength and human performance. 2nd ed. Philadelphia (PA): Lippincott Williams \& Wilkins; 2012.

Evans BW, Potteiger JA, Bray MC, Tuttle JL. Metabolic and hemodynamic responses to walking with hand weights in older individuals. Med Sci
Sports Exerc 1994;26:1047-1052.

Graves JE, Pollock ML, Montain SJ, Jackson AS, O'Keefe JM. The effect of hand-held weights on the physiological responses to walking exercise. Med Sci Sports Exerc 1987;19:260-265.

Kenney WL, Wilmore JH, Costill DL. Physiology of sport and exercise. 5th ed. Champaign (IL): Human Kinetics; 2012.

Knowlton RG, Brown DD, Bitter LJ, Sullivan JJ. Effects of hand held weights on the cardiovascular responses of trained and untrained women during walking. J Phys Educ Sport Sci 1992;4:7-14.

LaForgia J, Withers RT, Gore CJ. Effects of exercise intensity and duration on the excess post-exercise oxygen consumption. J Sports Sci 2006;24: $1247-1264$.

Makalous SL, Araujo J, Thomas TR. Energy expenditure during walking with hand weights. Phys Sportsmed 1988;16:139-148.

Maud PJ, Stokes GD, Stokes LR. Stride frequency, perceived exertion, and oxygen cost response to walking with variations in arm swing and hand-held weight. J Cardiopulm Rehabil 1990;10:294-299.

Morrow SK, Bishop PA, Ketter CA. Energy costs of self-paced walking with handheld weights. Res Q Exerc Sport 1992;63:435-437.

Mozaffarian D, Benjamin EJ, Go AS, Arnett DK, Blaha MJ, Cushman M, Das SR, de Ferranti S, Després JP, Fullerton HJ, Howard VJ, Huffman MD, Isasi CR, Jiménez MC, Judd SE, Kissela BM, Lichtman JH, Lisabeth LD, Liu S, Mackey RH, Magid DJ, McGuire DK, Mohler ER 3rd, Moy CS, Muntner P, Mussolino ME, Nasir K, Neumar RW, Nichol G, Palaniappan L, Pandey DK, Reeves MJ, Rodriguez CJ, Rosamond W, Sorlie PD, Stein J, Towfighi A, Turan TN, Virani SS, Woo D, Yeh RW, Turner MB; American Heart Association Statistics Committee; Stroke Statistics Subcommittee. Heart disease and stroke statistics-2016 update: a report from the American Heart Association. Circulation 2016; 133:e38-360.

Owens SG, al-Ahmed A, Moffatt RJ. Physiological effects of walking and running with hand-held weights. J Sports Med Phys Fitness 1989;29: 384-387.

Siri WE. Body composition from fluid spaces and density: analysis of methods. 1961. Nutrition 1993;9:480-491.

Wen CP, Wai JP, Tsai MK, Chen CH. Minimal amount of exercise to prolong life: to walk, to run, or just mix it up? J Am Coll Cardiol 2014;64: 482-484.

Yim YK, Park KS. The effect of short-term bed-rest on radial pulse in healthy subjects. J Acupunct Meridian Stud 2014;7:133-139.

Zarandona JE, Nelson AG, Conlee RK, Fisher AG. Physiological responses to hand-carried weights. Phys Sportsmed 1986;14:113-120. 